\title{
Is littoral cell angioma of the spleen as rare as previously believed in the pediatric population?
}

\author{
Ewa Matuszczak ${ }^{1}$, Joanna Reszec ${ }^{2}$, Wojciech Dębek ${ }^{1}$, Adam Hermanowicz ${ }^{1}$, \\ Lech Chyczewski $^{2}$
}

\author{
${ }^{1}$ Department of Pediatric Surgery, Medical University of Bialystok, Poland \\ ${ }^{2}$ Department of Medical Pathomorphology, Medical University of Bialystok, Poland
}

\begin{abstract}
Littoral cell angioma (LCA) is a rare primary splenic vascular tumor, originating from the littoral cells lining the red pulp sinuses of the spleen. There are only a handful of case reports of LCA in children to be found in the literature. We performed a retrospective analysis of the medical charts of pediatric patients with splenic lesions who were treated between 2005 and 2010 in the Pediatric Surgery Department of the Medical University of Bialystok. Surprisingly, LCA accounted for $37.5 \%$ of the splenic lesions found in our series. The majority of LCA tumors are benign, but given their malignant potential, splenectomy and long-term follow-up should be the gold standard for their management. We strongly support the use of further cross-sectional studies to properly elucidate the prevalence of littoral cell angioma of the spleen in the pediatric population. (Folia Histochemica et Cytobiologica 2012, Vol. 50, No. 3, 480-485)
\end{abstract}

Key words: littoral cell angioma, spleen, children, vascular tumor

\section{Introduction}

Littoral cell angioma (LCA) is a rare primary splenic vascular tumor originating from the littoral cells lining the splenic red pulp sinuses. LCA was first described by Falk et al. in 1991 [1]. To date, only a few case reports have been published of LCA in the pediatric population.

\section{Material and methods}

Between 2005 and 2010, eight children who were 8-17 years old were surgically treated because of cystic lesions of the spleen in the Pediatric Surgery Department of the Medical University of Bialystok. Our department is directly responsible for the pediatric population of Podlasie region, consisting of 300,000 children with the same ethnicity. All lesions were diagnosed incidentally during a USG examina-

Correspondence address: E. Matuszczak, Department of Pediatric Surgery, Medical University of Bialystok, Waszyngtona Str. 17, 15-274 Bialystok, Poland; tel.: + 488574509 24, fax: + 488574509 20;

e-mail: ewamat@tlen.pl tion of the abdomen, performed in most cases because of mild and/or intermittent abdominal pain. In three of the eight cases, histopathology showed a fibrous cyst wall consistent with a simple cyst, in one case a hamartoma of the spleen, and in another an epithelial splenic cyst. The remaining three cases demonstrated a littoral cell angioma (LCA), until now regarded as a very rare occurrence in the pediatric population. We subsequently performed a retrospective analysis of the medical charts for those patients who were diagnosed with a littoral cell angioma (LCA).

\section{Case reports}

An 11 year-old boy was admitted to our department because of an accidentally diagnosed splenic lesion. As a sports-team member, the boy underwent routine blood and urine tests. The urine test revealed mild erythrocyturia. His past medical history was uneventful, with no prior mention of any allergies. Further diagnostic ultrasound (US) of the abdomen revealed a well-circumscribed, hypoechogenic lesion, $6 \mathrm{~cm}$ in diameter, located at the inferior aspect of a normal-sized spleen. Bearing in mind the possibility of a former sports-related injury (the boy was a goal- 


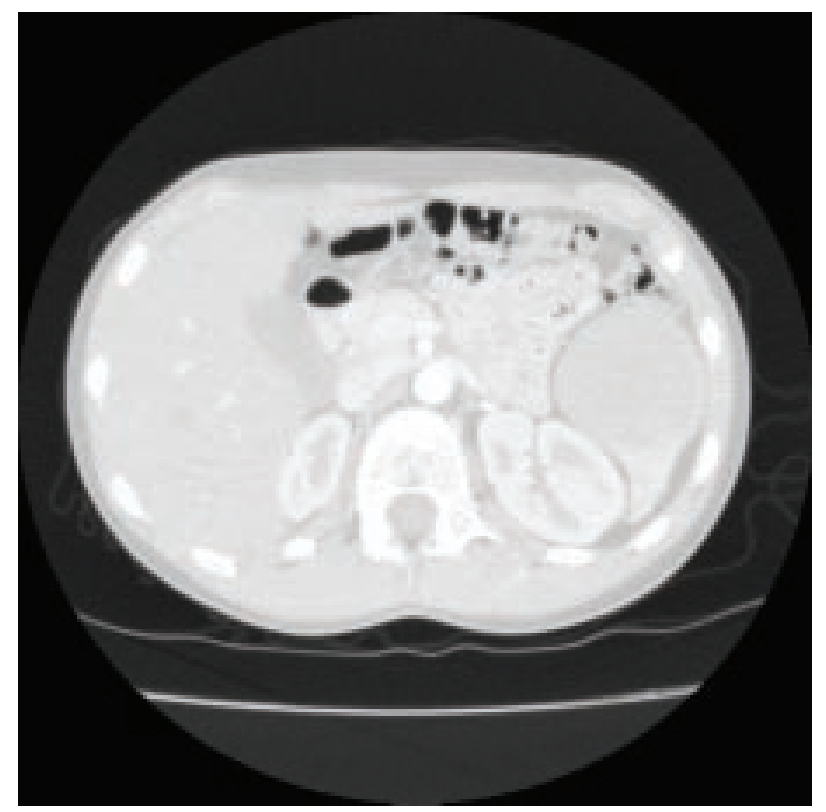

Figure 1. A hypodense lesion of the spleen, with some internal enhancement in the arterial and venous phases LCA on the contrast-enhanced CT scan

tender), the splenic lesion was further evaluated with a CT. A well-defined and hypodense lesion of the spleen, with some internal enhancement in the arterial and venous phases, was subsequently demonstrated on the contrast-enhanced CT scan (Figure 1). The CT also elucidated two small $(15 \times 10 \mathrm{~mm})$ additional spleens which were visible next to the hilum of the normal-sized spleen. The 5-minute delayed images further showed the lesion to be isodense when compared to the surrounding splenic parenchyma. The compilation of the aforementioned images suggested a vascular neoplasm of the spleen. The boy's hemoglobin, white blood cell, and platelet counts were all within normal limits. A decision was then made to carry out a splenectomy, without the use of a previous percutaneous, ultrasound-guided biopsy, due to the suspicion of a splenic hemangioma. At the time of the open splenectomy, the spleen was removed in its entirety for pathological evaluation. The additional spleens were left intact. The boy has had an uneventful post-operative recovery period, and reported no complaints at seven month follow-up.

In the second instance, a 13 year-old boy was evaluated for intermittent abdominal pain. He described episodes of left upper quadrant pain with no history of jaundice, nausea, vomiting, allergy or changes in bowel habits. Physical examination revealed mild splenomegaly. Hematological tests showed mild anemia (hemoglobin $11.6 \mathrm{~g} / \mathrm{dl}$ ), and normal platelets. Other laboratory tests confirmed that the liver and pancreatic enzymes, as well as the total bilirubin, were all within normal limits. An abdominal USG revealed a mildly enlarged $(109 \times 61 \mathrm{~mm})$ spleen with a round $(62 \times 55 \mathrm{~mm})$, ill-defined, heterogeneously hypoechoic focal lesion, containing small calcifications, which was localized next to the hilum of the spleen. No lymphadenopathy or other focal lesions were visible. A multiphase contrast-enhanced CT scan was performed to further the diagnosis. In addition to mild splenomegaly, a round, hypodense lesion was seen in the parenchyma of the spleen during the arterial phase, and could be localized near the hilum. It further showed mild progressive enhancement during early and late venous-phase imaging. No additional lesions were seen in the other abdominal solid organs, nor could any associated abdominopelvic lymphadenopathy be detected. Our presumptive diagnosis was hemangiomatosis, propelling us towards the decision of a splenectomy without first employing a percutaneous, ultrasound-guided biopsy. The spleen was thus surgically removed. The boy had an uneventful postoperative recovery period, and has remained well in a five year follow-up.

Lastly, a 10 year-old girl underwent a routine blood test and USG of the abdomen because of mild abdominal pain. There was no history of jaundice, nausea, vomiting, or changes in bowel habits. As an infant, the girl was evaluated by a physician due to an allergy to cow milk proteins. Present day physical examination however, did not reveal any changes in the abdominal cavity. Blood morphology, liver and pancreatic enzymes, as well as the total bilirubin levels, were all within normal limits. The abdominal US revealed a normal-sized spleen with a round $(81 \times 78$ $\mathrm{mm}$ ), well-defined, heterogeneously hypoechoic cystic lesion, localized in the upper pole of the spleen. No lymphadenopathy or other focal lesions were visible. No additional lesions were seen in the other abdominal solid organs, nor was any associated abdominopelvic lymphadenopathy detected. The suspicion of an innate cyst of the spleen was to be dealt with via excision, without the use of a prior percutaneous, ultrasound-guided biopsy. During laparoscopy, the lesion was defenestrated and its walls resected, while the rest of the spleen was left intact. Subsequent histological examination of the expunged tissue revealed a tumor, made up of large vascular spaces with small anastomotic vascular channels, consistent with a littoral cell angioma. The girl has had an uneventful post-operative recovery period, and has remained well in the one year of follow-up. Subsequent US diagnostics of the abdomen, carried out every three months, did not show any changes in the parenchyma of the spleen. The girl is still under ambulatory surveillance.

In all three of the aforementioned cases, histopathological diagnosis confirmed the presence of 
a littoral cell angioma. Biopsy tissue specimens were first fixed in a $10 \%$ buffered formalin solution, prior to being embedded in paraffin. They were then stained with hematoxylin and eosin, and subsequently examined under a light microscope. In order to obtain the proper diagnosis, immunohistochemical stains with the appropriate antibodies against CD31, CD34, vimentin, CD68 and Ki-67 (DAKO Cytomation), were used. Histologically, the tumors looked very similar to one another, resembling benign vascular tumors with distinct borders, and multiple blood-filled areas with anastomosing vascular canaliculi (Figures 2, 3), that showed lumen dilation. The tumor cells created narrowed channels, with large spaces that were lined by cuboidal cells, with vesicular nuclei and pale eosinophilic cytoplasm (Figure 4). No sign of any mitotic activity and/or necrosis were noted (Figures 3,4 ). The observed tumor cells also contained hemosiderin deposits and hyaline globules (Figure 5). Immunohistochemistry (Figure 6) further revealed that the cells showed positive immunoexpression for vimentin,

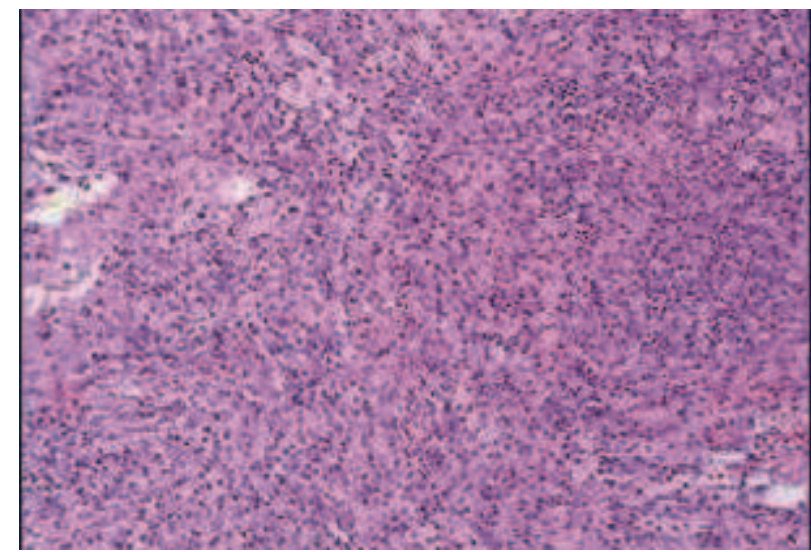

Figure 2. LCA - multiple blood-filled areas with anastomosing vascular canaliculi

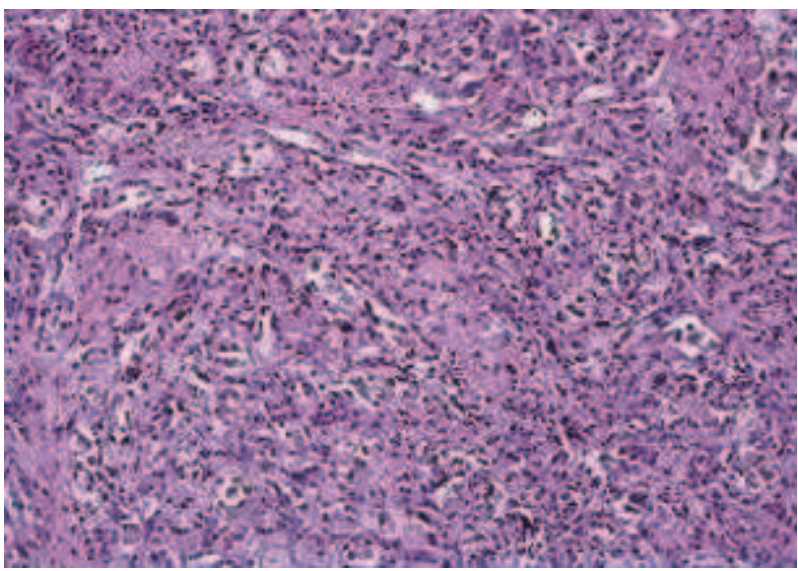

Figure 3. LCA - multiple blood-filled areas with anastomosing vascular canaliculi
CD31 (which suggests an endothelial cell tumor) and CD68 (a marker for histiocytic tumors). The noted mitotic activity (MIB-1) ranged between $1 \%$ and $3 \%$,

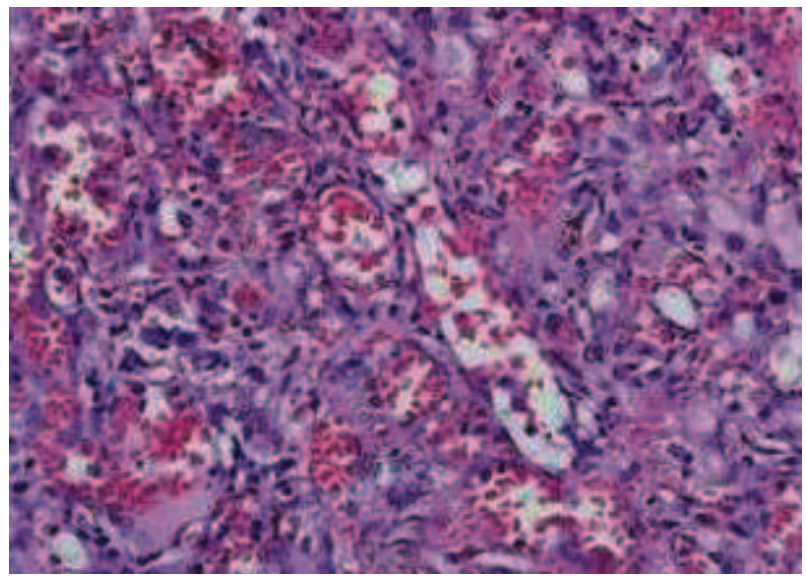

Figure 4. LCA cells create narrowed channels, with large spaces lined by cuboidal cells, with vesicular nuclei and pale eosinophilic cytoplasm

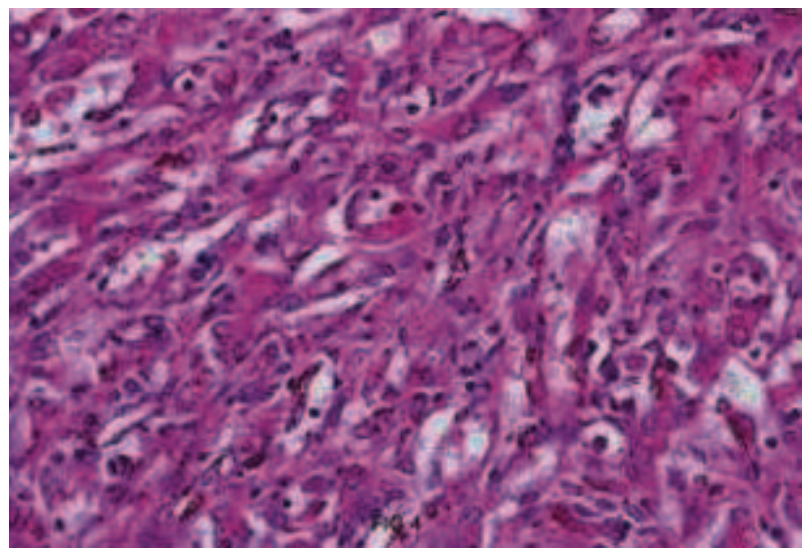

Figure 5. LCA — hemosiderin deposits and hyaline globules

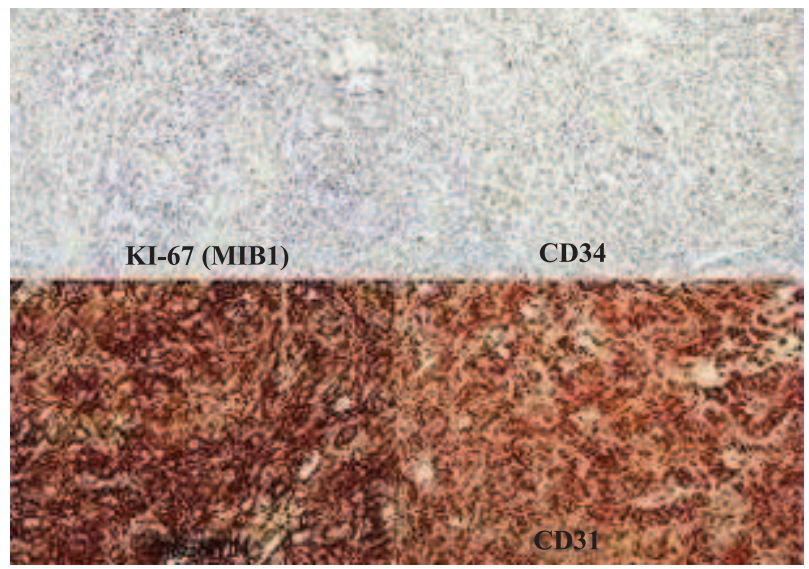

Figure 6. LCA Immunohistochemistry - positive immunoexpression for vimentin,CD31 and CD68 
thus excluding the possibility of a malignant vascular tumor.

The differential diagnosis included capillary and cavernous hemangiomas, as well as an angiosarcoma and epithelioid hemangioendothelioma. A cavernous hemangioma typically presents with dilated vascular spaces that are lined by flattened endothelium, as well microthrombi which are at different stages of organization, and are coupled with cytologically benign endothelial cells.

An angiosarcoma is defined as the presence of freely anastomosing vascular channels, often with spindle, pleomorphic or epithelioid cells that are marked by huge cellular atypia. Numerous mitotic figures and/or high mitotic activity is also frequently noted. Immunohistocytology reveals the angiosarcoma to be positive for endothelial markers (CD31, CD 34, Factor VIII), while the CD68 always remains negative.

Epithelioid hemangioendothelioma on the other hand, is a tumor defined by epithelioid cells instilled in a myxohyaline stroma, with the infiltration of sinusoids and vessels by intracytoplasmic lumina. Immunohistocytology reveals it to be positive for endothelial markers (CD31, CD 34, Factor VIII), and, as with an angiosarcoma, the CD68 is always negative.

\section{Discussion}

The commonest primary tumors of the spleen are of vascular origin [2]. Most are benign, and include hemangiomas and hamartomas. A splenic hamartoma is a rare, benign vascular proliferation that is often found incidentally while performing a work-up of other complaints, or at the autopsy. Histological findings consist of numerous, unorganized vascular channels of varying widths, with an intervening red pulp-like disorganized stroma, with or without lymphoid follicles. The endothelial cells are similar to those of normal splenic sinuses. Although rendering a diagnosis can be difficult, endothelial cells that are positive for CD8 are a key feature differentiating a hamartoma from other vascular lesions of the spleen [2-4].

Epithelial cysts account for approximately $20 \%$ of all splenic cysts. Their pathogenesis is unclear. It has been suggested that they are derived from embryonic epithelial inclusions during splenic development, and are formed as a result of either trauma, or the invagination of capsular surface mesothelium in the splenic sulci, leading to subsequent metaplasia [2-4].

Littoral cell angioma (LCA) is a vascular tumor of the spleen. It is a relatively recent finding, and only a few case reports have identified its malignant po- tential thus far $[1,3]$. The incidence of splenic hemangioma, which was first described by Falk et al. in 1991 , varies from $0.03 \%$ to $14 \%$ at the autopsy series [4]. Although there is no age predilection, LCA usually occurs in adults and appears to be extremely rare in children. Only a handful of pediatric cases have been reported thus far, making our histological findings in the pediatric spleen lesions all the more surprising $[1,5,6]$. Astonishingly, LCA accounted for $37.5 \%$ of all splenic lesions in our series. Clinically, LCA may be characterized as a solid mass occurring most often along with splenomegaly, thrombocytopenia or anemia, as well as fever of unknown origin. The symptoms of anemia, thrombocytopenia, and abdominal pain may well be associated with hypersplenism.

Grossly, there are two forms of LCA. More commonly, it is seen as a tumor consisting of multiple nodules diffusely involving the entire spleen. A rare solitary form has also been described, resembling the lesions in our patients [7]. The lesion can then be visualized on a CT scan, but the CT features of LCA are most often non-specific. Like most vascular tumors of the spleen, the LCA shows changes in density during delayed image testing [7]. Sonographic characteristics of LCA are no more helpful in their specificity, and include lobular splenomegaly with a diffuse, coarse, heterogeneous echo texture of the spleen, or a single echogenic mass that may contain cystic areas [4-6]. LCA that presents as multiple, small, hypodense nodules that may be seen during the portal venous phase of a contrast-enhanced CT, may well mimic a malignant process, such as metastatic disease, lymphoma, Kaposi's sarcoma, or any number of infections that may cause a microabscess [8].

In the first and last case presented by us, only the poles of the spleen were enlarged, whereas the second case showed a mild enlargement of the entirety of the spleen. As in our first case, LCA may be completely asymptomatic and represent an incidental finding made during imaging [1,9-11], or the patient may conversely present with abdominal pain - as described in our second and third examples, along with the possible symptoms of hypersplenism (anemia, thrombocytopenia and splenomegaly). This presents a diagnostic dilemma, since the differential diagnosis of such a lesion is thus made inadvertently complex [7].

At present, the final diagnosis is only possible via histopathological examination [5, 6, 12-14]. The lesions may be solitary or multiple, and are composed of vascular channels lined by cells that share the morphological and immunohistochemical findings characteristic for both the endothelial and histiocytic cells 
[15]. Microscopically, the lesions might be narrowed channels interspersed with large spaces that are lined by cuboidal cells, which contain hemosiderin deposits and/or hyaline globules. Atypical cells are absent, and mitotic activity is usually very low. High-field magnification typically reveals tall and plump sinuslining cells with little mitosis, and no cytologic atypia to suggest malignancy [11, 16-20].

Littoral cell angioma does however have the morphologic and immunohistochemical characteristics that differentiate it from other vascular splenic tumors. Immunohistocytologically, the tumor cells are positive for vimentin, CD31 CD68, CD21, CD8 and FVIIIrAg, while the Ki-67 index is likely to be very low $(\sim 1 \%)$, as previously described in the literature $[1,3,15,20,21]$.

The differential diagnosis for multiple splenic lesions thus includes both malignant and non-neoplastic disorders. Primary vascular tumors such as a hemangioma, hamartoma, hemangiopericytoma, hemangioendothelioma or angiosarcoma should therefore be the first ones taken into consideration, while other neoplastic processes such as a lymphoma, lymphangioma, visceral metastases, and/or granulomatous diseases should also not be overlooked.

Little is known about the potential for malignant transformation in LCA. To date, two subtypes of LCA with malignant potential have been described: littoral cell angiosarcoma and littoral cell cell hemangioendothelioma [15]. Patients affected by either may present with metastatic disease, even after undergoing a splenectomy. Histological evaluation is likely to further the diagnosis by revealing a marked abnormal architecture, nuclear atypia, necrosis, and CD68 immunonegativity [15].

Symptomatic LCA is often treated by splenectomy, given that several case reports have identified its malignant potential $[22,23]$. Bearing in mind the immunological disorders which may follow a pediatric splenectomy (as in our first case), the additional spleens which were present in that particular child were left intact.

Some authors have further described the association of LCA with autoimmune disorders (e.g. Crohn's disease, Gaucher's disease), and immune system dysfunction has been postulated as a possible pathogenic mechanism $[10,21]$. Other reports suggest that chronic infection and systemic immunosuppression may well contribute to LCA development [3,9]. This may explain the association of LCA with other types of cancer, such as thyroid, colorectal, renal, pancreatic, hematologic, ovarian and/or testicular neoplasms $[3,16,19,24-26]$. As a result of this potential correlation, some authors recommend close follow-up for all patients with LCA [16]. While reports of medical therapy with glucocorticoids and angioembolization of the splenic hemangiomas do exist, splenectomy is still considered to be the gold standard for the treatment of vascular splenic tumors $[2,4,19]$.

In conclusion, most LCA tumors are benign, but may present a challenging diagnostic dilemma for the physician. Given its malignant potential, splenectomy and long-term follow-up should be the gold standard of all LCA management. Bearing in mind, that LCA accounted for $37.5 \%$ of splenic lesions in our retrospective analysis, we believe that future crosssectional studies are needed to assess the prevalence of littoral cell angioma of the spleen in the pediatric population.

\section{Acknowledgements}

The authors would like to thank Agnieszka Stewart for her editorial assistance in the preparation of this manuscript.

\section{References}

1. Falk S, Stutte HJ, Frizzera G.: Littoral cell angioma. A novel splenic vascular lesion demonstrating histiocytic differentiation. Am J Surg Pathol. 1991;15:1023-1033.

2. Tan YM, Chuah KL, Wong WK. Littoral cell angioma of the spleen. Ann Acad Med Singapore. 2004;33:524-526.

3. Harmon RL, Cerruto CA, Scheckner A. Littoral cell angioma: a case report and review. Curr Surg. 2006;63:345-350.

4. Wilcox TM, Speer RW, Schlinkert RT, Sarr MG. Hemangioma of the spleen: presentation, diagnosis, and management. J Gastrol Surg. 2000;4:611-613.

5. Anton-Pacheco J, Ayuso RM, Cano I et al. Splenic littoral cell angioma in an infant. J Pediatr Surg. 2000;35:508-509.

6. Ertan G, Tekes A, Mitchell S, Keefer J, Huisman TAG. Pediatric littoral cell angioma of the spleen: multimodality imaging including diffusion-weighted imaging. Pediatr Radiol. 2009;39:1105-1109.

7. Arber DA, Strickler JG, Chen YY, Weiss LM. Splenic vascular tumors: a histologic, immunophenotypic, and virologic study. Am J Surg Pathol. 1997;21:827-835.

8. Kinoshita LL, Yee J, Nash SR. Littoral cell angioma of the spleen. Imaging features. AMJ Roentgenol. 2000;174:467-469.

9. Fadare O, Hileeto D, Mariappan MR. Multiple splenic lesions in a bacteremic patient. Arch Pathol Lab Med. 2004;128:1183-1185.

10. Gupta MK, Aguilera NS, Pastores GM. Littoral cell angioma of the spleen in a patient with Gaucher disease. $A m$ J Hematol. 2001;68:61-62.

11. Cosme A, Tejada A, Bujanda L et al. Littoral-cell angioma of the spleen: a case report. World J Gastroenterol. 2007;13:6603-6604.

12. Musgrave NJ, Williamson RM, O'Rourke NA, Searle JW. Incidentally discovered splenic vascular lesion. Pathology. 2002;34:579-581

13. Veillon DM, Williams RB, Sardenga LJ, Harrison GK, Cotelingam JD. "Little" littoral cell angioma of the spleen. Am J Surg Pathol. 2000;24:306-327. 
14. Ziske C, Meybehn M, Sauerbruch T, Schmidt-Wolf IGH. Littoral cell angioma as a rare cause of splenomegaly. Ann Hematol. 2001;80:45-48.

15. Hesse J, Bocklage T. Specimen fine-needle aspiration cytology of littoral cell angioma with histologic and immunohistochemical confirmation. Diagn Cytopathol. 2000;22:39-44.

16. Bisceglia M, Sickel JZ, Giangaspero F, Gomes V, Amini M, Michal M. Littoral cell angioma of the spleen: an additional report of four cases with emphasis on the association with visceral organ cancers. Tumori. 1998;84:595-599.

17. Chen LW, Chien RN, Yen CL, Chang LC. Splenic tumour: a clinicopathological study. Int J Clin Pract. 2004;58:924$-927$.

18. Collins GL, Morgan MB, Taylor FM 3rd. Littoral cell angiomatosis with poorly differentiated adenocarcinoma of the lung. Ann Diagn Pathol. 2003;7:54-59.

19. Johnson C, Goyal M, Kim B, Wasdahl D, Nazinitsky K. Littoral cell angioma. Clin Imaging. 2007;31:27-31.
20. Qu ZB, Liu LX, Wu LF, Zhao S, Jiang HC. Multiple littoral cell angioma of the spleen: a case report and review of the literature. Onkologie. 2007;30:256-258.

21. Suvajdzic N, Cemerikic-Martinovic V, Saranovic D et al. Littoral-cell angioma as a rare cause of splenomegaly. Clin Lab Haem. 2006;28:317-320.

22. Abbott RM, Levy AD, Aguilera NS, Gorospe L, Thompson WM. Primary vascular neoplasms of the spleen: radiologic-pathologic correlation. Radiographics. 2004;24:1137-1163.

23. Tee M, Vos P, Zetler P, Wiseman SM. Incidental littoral cell angioma of the spleen. World J Surg Oncol. 2008;19:87-92.

24. Akyildiz H, Akcan A, Soyuer I, Ibrahim Karahan O, Souzer E. Littoral cell angioma mimicking pancreatic tumour. Surgery. 2006;141:690-691.

25. Rana N, Ming Z, Hui MS, Bin Y. Case Report: Littoral cell angioma of spleen. Indian J Radiol Imaging. 2009;19:210-212.

26. Wang YJ, Li F, Cao F, Sun JB, Liu JF, Wang YH. Littoral cell angioma of the spleen. Asian J Surg. 2009;32:167-171.

Submitted: 4 September, 2011 Accepted after reviews: 8 January, 2012 